BMJ Open

Sport \&

Exercise

Medicine

\title{
Pragmatic posterior capsular stretch and its effects on shoulder joint range of motion
}

\author{
Keramat Ullah Keramat (D), ${ }^{1}$ Muhammad Naveed Babur ${ }^{2}$
}

To cite: Keramat KU. Naveed Babur M. Pragmatic posterior capsular stretch and its effects on shoulder joint range of motion. BMJ Open Sport \& Exercise Medicine 2020;0: e000805. doi:10.1136/ bmjsem-2020-000805

Accepted 25 August 2020
Check for updates

C Author(s) (or their employer(s)) 2020. Re-use permitted under CC BY-NC. No commercial re-use. See rights and permissions. Published by BMJ.

${ }^{1}$ Physiotherapy, Helping Hand Institute of Rehabilitation Sciences, Mansehra, Pakistan ${ }^{2}$ Isra Institute of Rehabilitation SciencesIsra Institute, Isra University, Islamabad, Pakistan

Correspondence to Keramat Ullah Keramat; karamatjee@yahoo. comkaramatjee@gmail.com

\section{ABSTRACT}

Objective To evaluate the immediate effects of pragmatic posterior capsular stretch (PPCS) on shoulder joint range of motion (ROM).

Method A quasi-experimental design was used to recruit healthy subjects of age $21.43( \pm 1.960)$ years, height 165.8 $( \pm 2.1069) \mathrm{cm}$ and weight $63.90( \pm 13.187) \mathrm{kg}$. Inclusion criteria were grade 1 and grade 2 of the shoulder mobility test of functional movement screening. Preintervention and postintervention measurement of flexion, abduction, internal rotation $(\mathrm{IR})$, external rotation $(\mathrm{ER})$, reaching up behind the back (RUBTB) and reaching down behind the neck (RDBTN) were compared. A therapist-administered PPCS was the only intervention applied.

Results Paired t-test statistics showed improvement (mean ${ }^{\circ} \pm \mathrm{SD}$ ) in shoulder flexion $\left(13.5^{\circ} \pm 8.11\right)$, abduction $\left(11^{\circ} \pm 8.35\right)$, IR $\left(8.5^{\circ} \pm 10.27\right)$, ER $\left(7.83^{\circ} \pm 7.15\right)$, RUBTB $\left(17.34^{\circ} \pm 13.81\right)$ inches and RDBTN $(2.93 \pm 1.52)$ inches. The changes in these ROM and functional movements were statistically significant $(p<0.05)$.

Conclusion PPCS can effectively improve the functional movement of RUBTB and shoulder ROM in healthy subjects. It is recommended for the trials on prevention and rehabilitation of shoulder pathologies.

Trial registration number NCT04242888.

\section{INTRODUCTION}

The mechanism of indirect shoulder injuries is under debate in the literature. Asymptomatic changes in the thoracic spine and shoulder girdle are considered the precursors of specific diagnoses such as subacromial impingements. ${ }^{12}$ One of the most prominent changes reported in this regard is scapular dyskinesis. ${ }^{2}$ The opinion of the researchers on shoulder pathology is gradually drifting towards posterior capsular tightness as a major culprit in relation to scapular dyskinesis and subsequent pathology. ${ }^{3-5}$ A cohort study reported a strong association of scapular dyskinesis and glenohumeral rotation deficits with the shoulder pain. ${ }^{6}$ Another study reported the presence of scapular dyskinesis for 9-24 months increases the risk of shoulder pain by $43 \%$ in an athletic population. ${ }^{78}$ It is theorised that glenohumeral internal rotation deficit is a result of posterior capsular
What are the new findings

- A novel posterior capsular stretch can effectively loosen the posterior capsule.

- Posterior capsular tightness is the precursor of indirect shoulder pathology.

- It can be used for prevention as well as rehabilitation of shoulder pathology especially in overhead athletes.

tightness, and scapular dyskinesis is its manifestation. ${ }^{78}$

It is observed that the repetitive overload during the deceleration phase of throwing leads to the hypertrophy of the posterior capsule, which forces the greater tuberosity of the humerus to translate superiorly - a useful observation that explains the mechanism of subacromial impingement. ${ }^{9}$ Therefore, a lax capsule is necessary for the optimum function of the shoulder.

To loosen the posterior capsule, a crossbody stretch, sleeper's stretch and modified stretches are used. The application of a crossbody stretch and a sleeper's stretch has been reported with an increase in range of internal rotation (IR) and external rotation (ER) in healthy subjects. ${ }^{5} 1011$ However, the scapula remains unstable during these stretches and therefore a modified stretch had been proposed and reported with better outcomes of IR and ER. ${ }^{12}$ All three stretches fail to address the torsional stress on the posterior capsule, which is mandatory in functional movements of reaching up behind the back (RUBTB) and reaching down behind the neck $(\mathrm{RDBTN}){ }^{8}$

\section{Objective}

A pragmatic posterior capsular stretch (PPCS) is designed to stretch the posterior capsule when it is in torsion. The purpose of this study is, therefore, to evaluate the effects of this novel technique on the shoulder range of motion (ROM) and its functional movements. 


\section{METHODOLOGY}

\section{Study design}

This single-group study of quasi-experimental design recruited 30 subjects in an equal proportion of males and females from a convenient sample of 18-30-year students of Helping Hand Institute of Rehabilitation Sciences. A sample size of 30 was deemed appropriate after a pilot trial on five healthy subjects with restricted shoulder mobility, which produced a meaningful difference of 15-degree change in abduction, and $3 \mathrm{~cm}$ difference in RUBTB, using SD estimates from previous studies. ${ }^{13} 14$ The primitive study design on healthy subjects was deemed appropriate since the intervention was novel and exploratory in nature. The sample included subjects of grade 1 or 2 on the shoulder mobility test of functional movement screening (FMS).$^{15}$ Both the grades indicate restriction in functional movement and shoulder ROM. Subjects with any pathology of the shoulder and with scores of Grade 0 (unable to bring arm behind the back) and Grade 3 (no restriction in shoulder mobility) on the same scale were excluded. An approved informed consent form was signed by each subject. This study design was approved by the Board of Advanced Study and Research of Isra International University Islamabad. This study represents one of the four arms of novel interventions registered on ClinicalTrials.gov (NCT04242888).

\section{Data collection and instruments}

The shoulder mobility tests of FMS were used to assess the RUBTB and RDBTN. ${ }^{15}$ Distance between the close bony prominences in each fist was measured before and after the intervention.

A digital inclinometer installed on a smartphone was used for measuring shoulder flexion, abduction, IR and ER. This method is reported with excellent reliability and concurrent validity. ${ }^{16} 17$ Abduction was measured with the shoulder in the ER and flexion with the shoulder in IR. This method was used for better visibility of the inclinometer. The phone was strapped to the wrist and the reading on the inclinometer was set to zero at $90^{\circ}$ shoulder abduction in a supine position on a Bobath's plinth for IR and ER, while abduction was measured in standing. All the ROM and functional movements were active in nature. This procedure for measuring each variable was repeated after the intervention.

\section{Intervention: PPCS}

PPCS was the only intervention used during the study. The subject is positioned in side-lying as shown in figure 1 . Label 1 shows the position of the thumb and fingers. The therapist stabilises the scapula in protraction through one hand and uses his/her other hand for longitudinal traction (label 2), medial rotation (Label 3) and extension (label 4) simultaneously. The semi-flexed elbow provides the necessary leverage, and the manoeuvre is performed in a way to mimic the active RUBTB. The stretch is maintained for $30 \mathrm{~s}$ combined with at least three deep breaths, and each breath is held in deep inspiration for around $8-10 \mathrm{~s}$. Three repetitions are performed. Intervention was given by well-trained and experienced male and female physiotherapists for their respective genders.

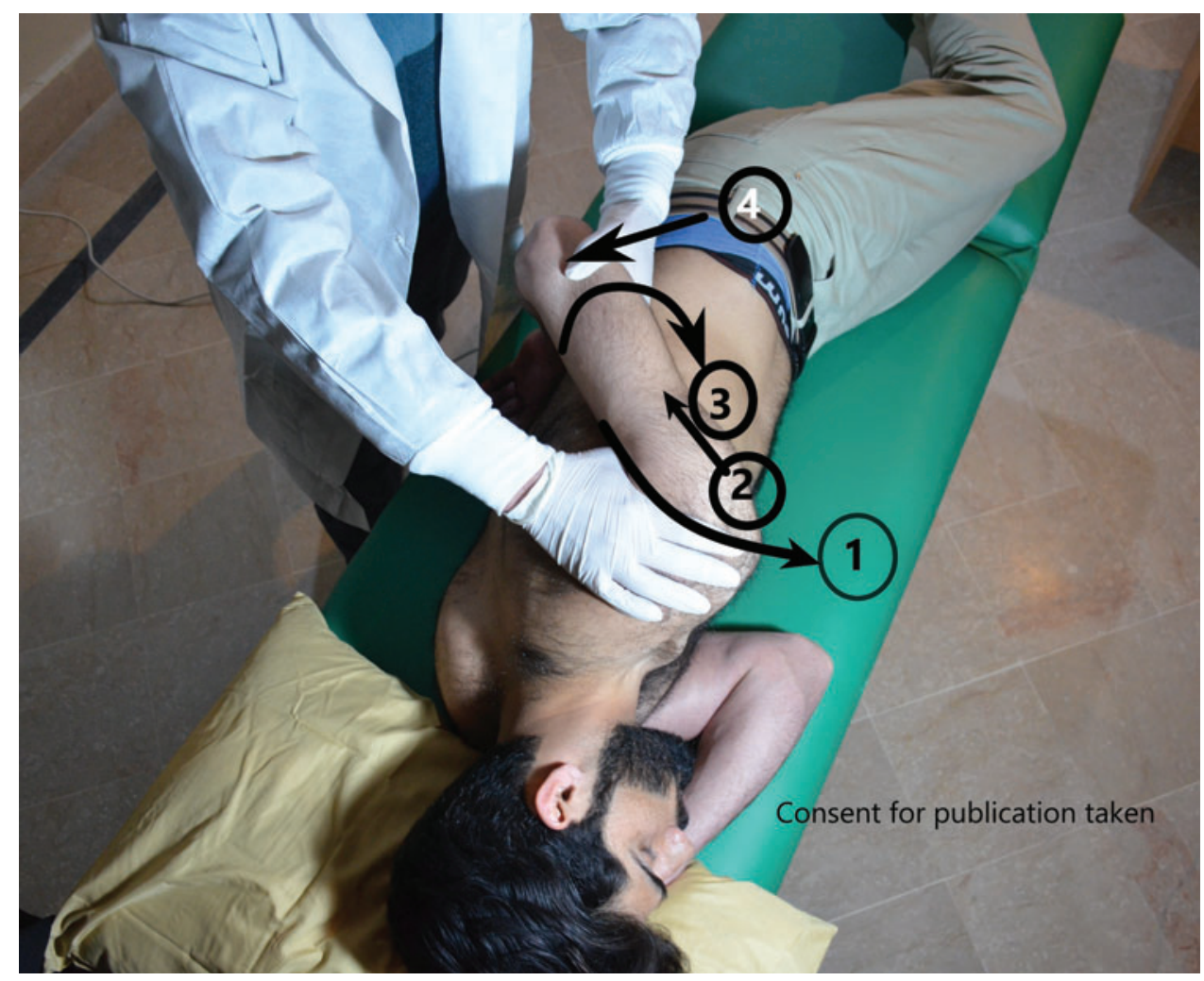

Figure 1 Novel posterior capsular stretch techniques. 
The principal investigator was not involved in the data collection and administration of the intervention. The intervention was given by senior physiotherapists. The data were collected by two male and two female undergraduate students before and after the intervention, for their respective genders under the supervision of senior physiotherapists. Mutual consensus for each measurement was reached by taking the mean value.

\section{Data analyses}

Descriptive statistics were computed for all variables. The normal distribution of the change in all dependent variables was computed through Kolmogorov-Smirnova and Shapiro-Wilk test. The mean and SD values of the pretest scores, posttest scores and the mean change in between each of the dependent variables were calculated using a paired t-test. Percentage change from the initial scores was calculated to show the amount of improvement in addition to the significant value. The effect size was calculated for each variable as the sample size appeared small.

\section{RESULTS}

The mean (SD) values for age, weight and height were $21.43( \pm 1.960)$ years, $63.90( \pm 13.187) \mathrm{kg}$ and 165.8 $( \pm 2.1069) \mathrm{cm}$, respectively. The dominant shoulder in 28 participants was the right, which was treated with the pragmatic stretch. Among the male participants; eight played cricket, five played volleyball and two played both; while eight females played badminton, two went to the gym and the remainder did not participate in any sport, though did carry out household chores such as putting objects on high shelves and hanging clothes for drying.

Data showed normal distribution on all the ROM $(p>0.05)$. Baseline statistics of shoulder ROM revealed limitation in almost all the mean values of ER, IR, flexion and abduction compared to the normative ROM values. Similarly, all values improved after improvement in RUBTB following an intervention. Detailed statistics are given in table 1. Paired t-test statistics revealed profound and significant improvements in all ranges. The effect size was calculated by dividing the mean change through the respective SD and through all the ROMs, a very large effect of more than 1 was found.

\section{DISCUSSION}

\section{Effects of PPSC and its analogy}

The results of this study reveal that a single session of PPCS can significantly and profoundly increase the shoulder ROM in healthy subjects. The improvement in each ROM was close to normal values. ${ }^{18}$ It is further observed that posterior capsular tightness has a direct relationship with rotation, abduction, flexion and RUBTB. Restriction in shoulder ROM was observed in association with the restriction in RUBTB at baseline and, once RUBTB improved due to PPCS, simultaneous improvement occurred in all the shoulder ROMs. These observations are consistent with the findings reported by Rosa et al in relation to the posterior capsular tightness. ${ }^{4}$

Improvement in shoulder ROM is also reported with the intervention of the cross-body stretch, sleeper's stretch and modified stretch. The improvement associated with these stretches is less pronounced and required a longer duration of 4-8 weeks. ${ }^{11} 1419$ However, the current study lacks follow-up measurements of ROM, which need to be explored.

\section{PPSC and RUBTB}

RUBTB requires extensibility of the posterior capsule in torsion, a factor which is lacking in the other forms of stretches which are aimed at lengthening the capsule in a longitudinal direction. PPSC is more specific to RUBTB and addresses the rotatory aspect of the posterior capsule, which makes it an effective intervention. In addition, sleeper's stretch and cross-body stretch do not accentuate the stability of the scapula, which is required because of greater tubercle adjustment and superior translation around $90^{\circ}$ of arm elevation as observed by McClure $e t a l .{ }^{20}$ Therefore, the stability of the scapula during the cross-body stretch and sleeper's stretch has been questioned and the modified stretch had been proposed. ${ }^{21}$ For this very reason, the PPCS emphasises the passive stability of the scapula.

Table 1 Range of motion before and after PPCS

\begin{tabular}{|c|c|c|c|c|c|c|}
\hline Range of motion & $\begin{array}{l}\text { Preintervention } \\
\text { Mean ( } \pm \text { SD) }\end{array}$ & $\begin{array}{l}\text { Postintervention } \\
\text { Mean ( } \pm \text { SD) }\end{array}$ & $\begin{array}{l}\text { Mean change } \\
X( \pm S D)\end{array}$ & $\begin{array}{l}\text { Per cent } \\
\text { improvement }\end{array}$ & $P$ value & $\begin{array}{l}\text { Cohen's d } \\
\text { value }\end{array}$ \\
\hline Flexion & $152.67^{\circ}\left(12.71^{\circ}\right)$ & $166.17^{\circ}\left(10.31^{\circ}\right)$ & $13.5^{\circ}(8.11)$ & $8.9 \%$ & $\leq 0.001$ & 1.66 \\
\hline Internal rotation & $53.67^{\circ}\left(13.38^{\circ}\right)$ & $62.17^{\circ}\left(12.57^{\circ}\right)$ & $8.5^{\circ}(10.27)$ & $15.9 \%$ & $\leq 0.001$ & 0.82 \\
\hline External rotation & $71.67^{\circ}\left(9.67^{\circ}\right)$ & $79.50^{\circ}\left(11.01^{\circ}\right)$ & $7.83^{\circ}(7.15)$ & $11.0 \%$ & $\leq 0.001$ & 1.09 \\
\hline RDBTN (cm) & $24.10(5)$ & $16.70(35)$ & $7.40(3.85)$ & $31 \%$ & $\leq 0.001$ & 1.92 \\
\hline
\end{tabular}

NPCS; RDBTN, reaching down behind the neck; RUBTB, reaching up behind the back. 
The PPCS resembles Mulligan's mobilisation with movement (MWM) for hand behind the back. ${ }^{22}$ Unlike Mulligan's MWM for hand behind the back movement, the PPSC includes stabilisation of the scapula in end range protraction, passive medial rotation, passive extension, the position of the therapist behind the back and patient position in side-lying-all combined with the deep breathing and administration duration of at least $30 \mathrm{~s}$.

\section{Recommendations and limitation}

The current report does not have a control group, and the results cannot be generalised. Therefore, the future studies on PPCS should be of multiple treatment sessions on multiple occasions, with a control group in both healthy subjects and subjects with shoulder pathology.

\section{CONCLUSION}

PPCS can effectively improve the functional movements (RUBTB, RDBTN) and shoulder ROM of healthy young adults, and is recommended for the trials on prevention and rehabilitation of shoulder pathology.

Acknowledgements The authors acknowledge Aisling Gaughran for proofreading and all the students for the collection of data.

Contributors MNB is my PhD supervisor and he contributed to the design, analysis and manuscript preparation.

Funding The authors have not declared a specific grant for this research from any funding agency in the public, commercial or not-for-profit sectors.

Competing interests None declared.

Provenance and peer review Not commissioned; externally peer reviewed.

Open access This is an open access article distributed in accordance with the Creative Commons Attribution Non Commercial (CC BY-NC 4.0) license, which permits others to distribute, remix, adapt, build upon this work non-commercially, and license their derivative works on different terms, provided the original work is properly cited, appropriate credit is given, any changes made indicated, and the use is non-commercial. See: http://creativecommons.org/licenses/by-nc/4.0/.

ORCID iD

Keramat Ullah Keramat http://orcid.org/0000-0002-1847-1850

\section{REFERENCES}

1 Alizadehkhaiyat O, Roebuck MM, Makki AT, et al. Postural alterations in patients with subacromial impingement syndrome. Int J Sports Phys Ther 2017; $12: 1111$.

2 Turgut E, Baltaci G. Effect of flexibility deficit on scapular asymmetry in individuals with and without shoulder pain. $\mathrm{Br} J$ Phys Ther 2018;22:370-5

3 Duzgun I, Turgut E, Çinar-Medeni Ö, et al. The presence and influence of posterior capsule tightness on different shoulder problems. J Back Musculoskelet Rehabil 2017;30:187-93.

4 Rosa DP, Borstad JD, Ferreira JK, et al. The influence of glenohumeral joint posterior capsule tightness and impingement symptoms on shoulder impairments and kinematics. Phys Ther 2019;99:870-81.

5 Taşpinar F, Akkan H, Saraçoğlu İ, et al. Immediate effects of posterior capsule stretching exercise in individuals with total arc of motion deficit. Turk J Physiother Rehabil 2019;30:112-18.

6 Clarsen B, Bahr R, Andersson SH, et al. Reduced glenohumeral rotation, external rotation weakness and scapular dyskinesis are risk factors for shoulder injuries among elite male handball players: a prospective cohort study. Br J Sports Med 2014;48:1327-33.

7 Hickey D, Solvig V, Cavalheri V, et al. Scapular dyskinesis increases the risk of future shoulder pain by $43 \%$ in asymptomatic athletes: a systematic review and meta-analysis. Br J Sports Med 2018;52:102-10.

8 Keramat UK. Conservative treatment preferences and the plausible mechanism of Neer's stage 1 of shoulder impingement in younger people. J Pak Med Assoc 2015;65:542.

9 Takenaga T, Sugimoto K, Goto H, et al. Posterior shoulder capsules are thicker and stiffer in the throwing shoulders of healthy college baseball players: a quantitative assessment using shear-wave ultrasound elastography. Am J Sports Med 2015;43:2935-42.

10 McClure $\mathrm{P}$, Balaicuis J, Heiland D, et al. A randomized controlled comparison of stretching procedures for posterior shoulder tightness. J Ortho Sports Phys Ther 2007;37:108-14.

11 Chepeha JC, Magee DJ, Bouliane M, et al. Effectiveness of a posterio shoulder stretching program on university-level overhead athletes: randomized controlled trial. Clin J Sport Med 2018;28:146-52.

12 Tahran Ö, Yeşilyaprak SS. Effects of modified posterior shoulder stretching exercises on shoulder mobility, pain, and dysfunction in patients with subacromial impingement syndrome. Sports Health. 2020:1941738119900532.

13 Tejera-Falcón E, Del Carmen Toledo-Martel N, Sosa-Medina FM, et al. Dry needling in a manual physiotherapy and therapeutic exercise protocol for patients with chronic mechanical shoulder pain of unspecific origin: a protocol for a randomized control trial. BMC Musculoskelet Disord 2017;18:400.

14 Tahran Ö, Yeșilyaprak SS. Effects of modified posterior shoulder stretching exercises on shoulder mobility, pain, and dysfunction in patients with subacromial impingement syndrome. Sports Health 2020;12:139-48.

15 Cook G, Burton L, Hoogenboom BJ, et al. Functional movement screening: the use of fundamental movements as an assessment of function-part 2. Int J Sports Phys Ther 2014;9.

16 Boissy P, Diop-Fallou S, Lebel K, et al. Trueness and minimal detectable change of smartphone inclinometer measurements of shoulder range of motion. Telemed E-health 2017;23:503-6.

17 Smith AB Validation of a smartphone application for measuring shoulder internal rotation and external rotation range of motion with intra-rater reliability. 2016.

18 Gill H, Gustafsson L, Hawcroft L, et al. Shoulder joint range of motion in healthy adults aged 20 to 49 years. Br J Occupational Ther 2006;69:556-61.

19 Tate AR, Mcclure PW, Young IA, et al. Comprehensive impairment-based exercise and manual therapy intervention for patients with subacromial impingement syndrome: a case series. J Ortho Sports Phys Ther 2010;40:474-93.

20 Lukasiewicz AC, McClure P, Michener L, et al. Comparison of 3-dimensional scapular position and orientation between subjects with and without shoulder impingement. J Ortho Sports Phys Ther 1999;29:574-86.

21 Wilk KE, Hooks TR, Macrina LC. The modified sleeper stretch and modified cross-body stretch to increase shoulder internal rotation range of motion in the overhead throwing athlete. $J$ Ortho Sports Phys Ther 2013;43:891-4.

22 Satpute $\mathrm{KH}$, Bhandari P, Hall T. Efficacy of hand behind back mobilization with movement for acute shoulder pain and movement impairment: a randomized controlled trial. J Manipulative Physiol Ther 2015;38:324-34. 